\title{
A psychometric evaluation of the 17-itemed Utrecht Work Engagement Scale in Uganda
}

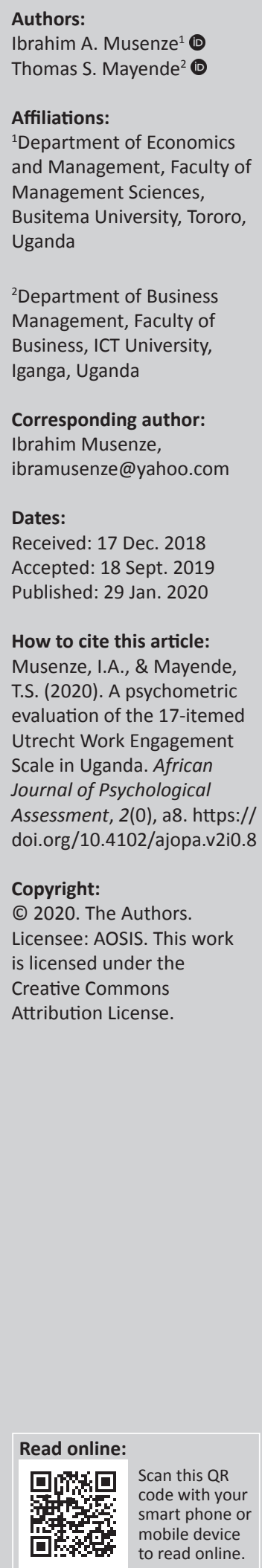

\begin{abstract}
This study aimed at the establishment of the psychometric properties of the 17-itemed Utrecht Work Engagement Scale (UWES-17) itemed factorial structure. This was done by examining the similarities and differences in terms of model fit of the tri-factor model to a one-factor model. Using a cross-sectional design, confirmatory factor analysis was used to evaluate the 17-item uni-dimensional and the 17-item tri-factor UWES respectively on a sample of 323 education assistants (professional teachers) in Uganda. The study confirmed an 11 -item trifactor Uganda's primary school sample (UWES-Ug) as a reliable and parsimonious factor structure within this cohort. The sample was restricted to teachers and this limits the generalisability of the findings. On account of these results, the study sample evidently attests to the fact that work engagement is best represented as a tri-factor construct in the Ugandan context. This study contributes to theory by confirmation of the three-factor structure of work engagement in developing countries through use of perceptual data from a Ugandan sample. This is a pioneer empirical study that validates the UWES 17-itemed scale in Uganda.
\end{abstract}

Keywords: UWES-Ug; UWES-17; psychometric evaluation; work engagement; Uganda.

\section{Introduction}

Engaged teachers can be conceptualised as teachers 'who feel energetic and dedicated, and are absorbed by their work' (Bakker, Schaufeli, Leiter, \& Taris, 2008, p. 188). This implies that such personnel work hard (have vigour), are immensely involved in teaching work (are dedicated) and feel happily engrossed (are absorbed) in their work (Bakker et al., 2008). These teachers experience positive emotions comprising happiness, joy and enthusiasm; experience enhanced psychosomatic health; are capable of designing their own job and personal resources (like getting support from others) and transmit their engagements to others (Bakker et al., 2008).

The issue of engaged teachers is now a global matter. For instance, because of its importance, a scale has been developed to better visualise it (Sasmoko, Doringin, Indrianti, Goni, \& Ruliana, 2018). Annual attrition rates have been on the rise in the teaching profession, and more interestingly, many teachers report low levels of engagement (OECD, 2005). Past studies suggest that highly engaged teachers are less likely to want to quit their jobs (Klassen et al., 2013); yet, low attrition levels among teachers do not necessarily signify high levels of engagement.

Over the years, Uganda has persistently faced acute and unequal distribution of its primary school teachers across regions and schools (MoES, 2016). Attrition levels among primary school teachers were severe following the introduction of universal primary education (UPE) in 1997. The inception of UPE resulted in high pupil enrolment, necessitating mass teacher recruitment, and meanwhile, salaries for the teachers have been gradually rising, though still low (MoES, 2014b). Between 1997 and 2010, enrolment shot up from 2.9 million to over 8.0 million (MoES, 2014b), and since then, the number is increasing steadily. The UPE programme has increased workload leading to a poor pupil-teacher ratio (PTR). According to the Education Management Information System report (2014a), in 2001, the PTR in government-aided schools was 98:1, while in privately run schools, it was at 58:1. This has since improved to 54:1, though it is still above the national average target of 45:1. As a result, the government of Uganda via the implementing body (the Ministry of Education and Sports), adopted some policy interventions including the construction and rehabilitation of schools; buying of text books and co-curricular materials; implementation of teacher training and development policies; implementation of measures to deal with teacher absenteeism (hard-to-reach, hard-to-stay); and strategies for teacher retention and syllabi reforms among others (MoES, 2014b). Besides, unqualified teachers, hereafter referred to as licenced teachers (LTs) were recruited for the delivery of primary education services. Though LTs proved to be useful over time, challenges related to competence persisted. It is worth pointing 
out that both LTs and qualified teachers in Uganda, remained vulnerable to high rates of attrition (MoES, 2014a, 2014b, 2016).These policy interventions are yet to materialise into completely reasonable enrolment and retention rates as will be determined through regular staff head-counts.

Attrition levels are predominantly high in the countryside where, in addition to greater need, teachers grapple with an increased workload because of massive pupil enrolment, poor remuneration, hard-to-reach areas and lack of or poor accommodation facilities (Kagolo, 2013). Attrition denotes a reduction in the number of workers as a result of retirement, resignation or death and attrition rate refers to reduction rate in size or number of workers (India, 2019). Primary school teacher attrition rates differ widely across diverse settings and agenda (Kagolo, 2013; MoES, 2014a), signifying an array of interacting factors such as engagement that determine primary school teachers' decision to remain working in a particular school.

Research has repetitively confirmed that workers who are engaged in their work contribute considerably to quality service delivery, productivity and innovation (Konermann, 2012; Salanova, Agut, \& Peiró, 2005). Engaged workers exhibit extraordinary energy and enthusiasm at work. Therefore, work engagement has significant effects for organisations. It does not only trigger exceptional performance, but also enhances organisational commitment and customer loyalty (Halbesleben, 2010; Salanova et al., 2005).

According to Vallières and McAuliffe (2015), Carr et al. (2012), Vallières, McAuliffe, Hyland, Galligan and Ghee (2017), organisational psychology (OP) is increasingly considered a significant field to help overcome the current challenges of human resources in organisations. Organisational psychology has the unique ability to broaden our present perception of the issues that lower staff attrition. An appropriate grasp of the psychological issues that contribute to a durable teacher engagement in their workplaces is regarded important (Wurie, Samai, \& Witter, 2016). Current research calls for greater and better evidence to lessen high attrition levels through the development and at some point, the testing of the level of engagement using a durable and reliable tool. In view of this, the Utrecht Work Engagement Scale (UWES), a 17-itemed variant, has been adopted and used among employees both in the highly-developed and mid-developed countries (Ahmed, Majid, \& Zin, 2016; Shimazu et al., 2008; Storm \& Rothmann, 2003). Presently, available research examining the scales' factorability, reliability and validity for individuals from low-developed countries, with the exception of Vallières, et al.'s study of 2017 in Sierra Leone, is limited, and specifically invisible in Uganda. This study is therefore a response to the calls for testing of the UWES in different multi-cultural settings (cf. Balducci, Fraccaroli, \& Schaufeli, 2010; Petrović, Vukelić, \& Čizmić, 2017; Schaufeli \& Bakker, 2003; Schaufeli, Bakker, \& Salanova, 2006).

Also, though earlier studies have revealed acceptable reliability and validity under diverse contexts; for instance, in a multi-national setting involving some European, Scandinavian and African countries (Schaufeli et al., 2006), in Brazil (Vazquez, dos Santos Magnan, Pacico, \& Hutz, 2015) and in Hong Kong (Fong \& Ho, 2015), to mention but a few, there remain many unsettled issues surrounding the scale's dimensionality, or whether its replication would provide similar results across continents and countries.

Moreover, debates on the UWES are yet to be reconciled and present several lacunae. For instance, some evidence suggests that a nine-item uni-dimensional scale, presents better and robust results over the three-factor 17-itemed scale (Schaufeli et al., 2006; Seppälä, Mauno, Hakanen, Kinnunen, Tolvanen, \& Schaufeli, 2009). Further, it is still unclear if the threedimensional, 17-item UWES (Schaufeli \& Bakker, 2003) offers identical and reliable results along contrasting demographics and work situations (Seppälä, et al., 2009). Factorial frameworks meeting acceptable thresholds abound. Some support has been provided for the uni-dimensional factor structure (Alok, 2013; De Bruin, Hill, Henn, \& Muller, 2013; Fong \& Ho, 2015; Sautier et al., 2015; Shimazu et al., 2008; Vallières et al., 2017), some for the bi-factor model (Kulikowski, 2017) and some for the original tri-factor model (Hadassah \& Balducci, 2013; Lathabhavan, Balasubramanian, \& Natarajan, 2017). Therefore, the findings in regards to the UWES' dimensionality are still inconclusive.

For the case of Uganda, a dearth of studies providing evidence relating to the UWES application exists. Therefore, testing the psychometric properties of the UWES (Schaufeli \& Bakker, 2003) specifically in Uganda, and sub-Saharan Africa in general, might contribute to knowledge growth in terms of its validation, generalisation in developing countries and application in workplace situations. Its properties need to be re-examined so that it can be applied in individual and organisational settings with more rigour. To fill the above gaps, we set to examine the psychometric properties of the UWES-17. The specific objectives were, (1) to evaluate the factorial validity by comparing the fit of the tri-factor model to that of the uni-factor model (which assumes that all items load on one single underlying dimension), (2) examine the scale's reliability using Cronbach's alpha coefficient on a Ugandan sample.

\section{Methods \\ Participants}

From a total population of 1700 education assistants (primary school teachers), as obtained from the updated staff list from the Directorate of Human Resources as of 30 January 2018 - from a district local government in Uganda, a sample of 323 respondents were selected to complete the UWES-17 questionnaire. However, only 225 questionnaires were retrieved and therefore, judged usable. The usable questionnaires constituted a response rate of about $70 \%$. Participants were neither identified by names in the research process nor coerced into taking part in the study - they could leave at any stage of the research. The mean age was 
$38-48$ years $(\mathrm{SD}=10.00)$, with $54 \%$ being female. In terms of educational background, $45 \%$ of the sample had, at the least, graduated from higher educational institutions, with a diploma in education, while, the majority (55\%), had a basic certificate in education. In order to draw a sample for this study, we relied on suggestions by Yamane (1967), and Krejcie and Morgan (1970), generating a sample of 323 and 313 respectively. We used a sample size of 323 based on Yamane's guidelines because it gives exact values. Later, we adopted a simple random technique to draw a sample of 323 participants from a population of 1700 primary school teachers. We considered the following inclusion criteria: all participants had to be formally employed and duly appointed by the district service commission (a body charged with primary teachers' recruitment in the district as either education assistants, senior education assistants, principal education assistants, deputy head teachers, and head teachers).

\section{Measures}

In order to evaluate work engagement, the UWES's short version UWES-17 (Schaufeli \& Bakker, 2003) was adopted. This is a self-report scale that was scored on a 5-pont Likert rating scale: 1 (strongly disagree) to 5 (strongly agree). Vigour was assessed using six items, dedication using five and absorption using six questions. The choice of UWES-17 was dictated by its extensive usage, parsimony in terms of empirical validation and its capacity to evaluate staff's work engagement regardless of their specialised and work-related focus (Seppälä, 2013; Sinval, Pasian, \& Marôco, 2018). Since Uganda uses English as an official language, and considering that all the respondents were literates, there was no need for back and forth translations.

\section{Procedures}

Consistent with the work of Hinkin (1998), in order to develop and test the adequacy of the UWES tool, we conducted a pilot test on 10 employees from private primary schools. The respondents filled in a self-report tool (UWES17). Using the district education officer, and the district constituent inspectors as contact persons, we accessed the respondents and distributed the questionnaires for completion. The participation was voluntary and respondents were not required to indicate their names on the questionnaire. Out of 323 questionnaires that were physically distributed, 225 were retrieved constituting a response rate of approximately $70 \%$. An attempt was undertaken to explain the aim of the study to participants. The authors ensured the participants consent was given by means of signed consent forms that were completed before commencing the study.

\section{Statistical analysis}

In validation of the scale, a confirmatory factor analysis technique executed in AMOS 21.0 (Arbuckle, 2012) was relied on. The psychometric validity of two UWES versions (i.e., the 17-itemed uni-dimensional scale, and the 17-itemed three-factor scale) was validated. Confirmatory factor analysis
(CFA) was conducted using the maximum likelihood estimation procedure to determine the appropriateness of both the uni-dimensional and tri-factor models. The goodness of fit of the models was assessed based on the following conventional benchmarks: the goodness of fit index (GFI) $\geq 0.8$, adjusted goodness of fit index (AGFI) $\geq 0.8$, Tucker-Lewis index (TLI) $\geq$ 0.9 , the comparative fit index $(\mathrm{CFI}) \geq 0.9$ and the root mean square error of approximation (RMSEA) $\leq 0.06$ (Hu \& Bentler, 1998). To examine the reliability of the scale, Cronbach's alpha coefficients $(\alpha)$ that were the determinants of internal consistency and homogeneity were assessed. Cronbach's alpha coefficients $(\alpha)$ having a value of 0.70 and above were used as the cut-off threshold (Amin, 2005; Nunnally \& Bernstein, 1994). The above test posted values of 0.86 , and 0.72 for the uni-dimensional and tri-factor models respectively.

\section{Fit indices}

We used multiple fit indices to evaluate model fit (for instance, absolute and incremental). The absolute model fit was examined with the Chi-square $\left(\chi^{2}\right)$ index and the fit of the alternate models was compared with the $\chi^{2}$ difference test consistent with Satorra and Bentler's (2001) guidelines. Rule of the thumb suggests that a non-significant $\chi^{2}$ statistic signifies robust model fit (Kline, 2011). Further, in the $\chi^{2}$ difference test, a non-significant decrease in $\chi^{2}$, relative to the change in the number of degrees of freedom $(d f)$, shows that the constrained model is satisfactory. The baseline model is more acceptable if there is a significant reduction in $\chi^{2}$. The models' fits were also assessed through other fit statistics. The RMSEA (Browne \& Cudeck, 1993) provides an estimate of the difference between the hypothesised model and the true population model. RMSEA adjusts for errors of approximation in the population (Bollen, 1989). RMSEA depicts the error of approximation and the values of 0.06 and below indicate better fit of the model (Hu \& Bentler, 1998); values less than 0.08 but above 0.06 indicate reasonable model fit; while values above 0.08 indicate poor model fit (Browne \& Cudeck, 1993). The incremental fit of the models was assessed through the non-normed fit index (NNFI), and the CFI. The NNFI and CFI measure model improvement by comparing the hypothesised model's fit statistics with an independence model. According to $\mathrm{Hu}$ and Bentler (1999), the CFI and NNFI statistics of 0.95 and above indicate good model fit. We also adopted goodness of fit (GFI) and AGFI. According to Kim (2007), GFI and AGFI values that are above 0.90 indicate acceptable fit statistic.

\section{Common method variance}

In order to minimise common method biases, and given that the data were collected from the same source, we undertook several safeguards based on the recommendation of Podsakoff, MacKenzie and Podsakoff (2012) and Williams and McGonagle (2016). Initially, respondents were informed that their identities were to remain anonymous and information gathered from them would remain confidential. None of them had to fill in their names in the survey instrument. Secondly, instead of grouping questionnaire 
items under the construct to which they were associated, the items were randomly ordered. This technique aided in the reduction of the probability of priming effects produced by item entrenchment (embeddedness). Thirdly, three survey sessions were conducted a week apart, which helped to suppress consistency themes. We additionally conducted the Harman's one-factor test to spot the common method bias threat (Podsakoff, MacKenzie, \& Podsakoff, 2003). In this analysis, the first factor did not account for the greatest variance $(30.1 \%)$, which is less than the $50 \%$. All factors explained $68.3 \%$ of the total variance. This finding further suggests a tolerable common method bias.

\section{Ethical considerations}

Prior to carrying out this study, ethical clearance was obtained from the Faculty of Management Sciences of Busitema University under the ethical clearance number: FGSEC No. 14/18/2.

\section{Results \\ Descriptive statistics}

The means, standard deviations and inter-correlations of the variables are reported in Table 1 . Dedication is positively related to vigour $(r=0.450, p<0.01)$, and absorption is positively related to vigour $(r=0.347, p<0.01)$ and dedication $(r=0.520, p<0.01)$.

\section{Factorial validity of the Utrecht Work Engagement Scale in Uganda}

The CFA results of the uni-dimensional and the tri-factor models of the UWES-17 in Ugandan context are shown in Table 2 and Figures 1 and 2. Regardless of the underlying factor structure, uni-dimensional model of the UWES-17 fits the data poorly with RMSEA of 0.103 beyond the mentioned criteria. The Chi-square test $\left(\chi^{2}=399.412 / d f=119\right)$ was significant $(p=0.000)$, well above the acceptable limits. Other fit indices such as CFI (0.327), NFI (0.277), TLI (0.251), GFI (0.811), and AGFI (0.757) were below the prescribed criteria.

For the tri-factor UWES-17 model, a slightly acceptable fit to data was established. RMSEA was 0.067 , which met the threshold values of below 0.08 (Browne \& Cudeck, 1993). The lower Chi-square, from the Chi-square test was marginally better compared to the uni-dimensional model $\left(\chi^{2}=231.369 / d f=116\right)$, and the model was significant $(p=0.004)$. Other fit indices such as CFI $(0.721)$, NFI (0.681), TLI (0.675), GFI (0.896) and AGFI (0.862), though below the prescribed criteria, were marginally acceptable in comparison to the uni-dimensional model. In view of the above, the tri-factor model of the UWES-17 moderately fit the data. Therefore, further analysis was based on the tri-factor model of the UWES-17.

\section{Post hoc analyses}

Given the moderate, but not acceptable fit of the tri-factor model of the UWES-17, the attention moved from model test to model development. In view of the high standardised residuals of six items: that is vigour $=$ item 4 , item 5 and item 6 ; dedication $=$ item 4 , and item 5 and absorption = item 5 , a decision was taken to re-specify the model with the above items deleted, one at a time. Model re-specification was therefore based on further scrutiny of descriptive and reliability statistics, the modification indices and on theoretical considerations (Schaufeli, Salanova, GonzalezRoma, \& Bakker, 2002). Therefore, the tri-factor model was re-specified with its parameters freely estimated. The respecified tri-factor model showed better fit of the data $\left(\chi^{2}=\right.$ $46.870 / \mathrm{df}=41)$ and was non-significant $(p=0.244)$. Analysis revealed a RMSEA of 0.025 , which met the prescribed criteria of less than 0.06 (Browne \& Cudeck, 1993). Other fit indices such as CFI (0.969), NFI (0.952), TLI (0.958), GFI (0.965) and AGFI (0.964), showed that the re-specified model was robust as it appropriately fit the data. We therefore, confirmed an 11-item tri-factor UWES-17 model in Uganda's primary school sample (UWES-Ug). The fit statistics are presented in Table 3, while the standardised factor and descriptive statistics for the confirmed 11 item tri-factor UWES-17 model is shown in Table 4 and Figure 3. Further, the critical ratio values used for determining the level of statistical significance for estimated parameters for the scale items were within the range of 34.087 and 86.487 , well above the suggested minimum of $> \pm 1.96$ and all the items were statistically significant at 0.001 .

TABLE 1: Means, standard deviations and inter-correlations among variables $(N=225)$.

\begin{tabular}{|c|c|c|c|c|c|c|c|c|}
\hline \multicolumn{2}{|c|}{ Variables } & \multirow{2}{*}{$\begin{array}{c}\boldsymbol{M} \\
31.58\end{array}$} & \multirow{2}{*}{$\begin{array}{c}\text { SD } \\
6.56\end{array}$} & \multirow{2}{*}{$\begin{array}{c}\text { (1) } \\
1\end{array}$} & \multirow{2}{*}{$\begin{array}{c}\text { (2) } \\
-\end{array}$} & \multirow{2}{*}{$\begin{array}{c}\text { (3) } \\
-\end{array}$} & \multirow{2}{*}{$\begin{array}{c}\text { (4) } \\
-\end{array}$} & \multirow{2}{*}{$\begin{array}{l}\text { (5) } \\
-\end{array}$} \\
\hline 1. & Age & & & & & & & \\
\hline 2. & Gender & 0.42 & 0.50 & 0.14 & 1 & - & - & - \\
\hline 3. & Vigour & 5.01 & 4.44 & 0.60 & $0.320 * *$ & 1 & - & - \\
\hline 4. & Dedication & 4.41 & 0.86 & -0.17 & $0.280 * *$ & $0.450 * *$ & 1 & - \\
\hline 5. & Absorption & 5.03 & 1.15 & -0.18 & $0.053^{* *}$ & $0.347^{* *}$ & $0.520 * *$ & 1 \\
\hline
\end{tabular}

SD, standard deviation.

$$
* *, p<0.01 \text {. }
$$

TABLE 2: Confirmatory factor analysis results.

\begin{tabular}{lcccccccccc}
\hline Scale & $\chi \mathbf{2}$ & $\boldsymbol{d} \boldsymbol{f}$ & $\boldsymbol{p}$ & RMSEA & GFI & AGFI & CFI & TLI & 0.327 & 0.251 \\
1-factor & 399.412 & 119 & 0.000 & 0.103 & 0.811 & 0.757 & 0.277 & 0.862 & 0.721 \\
3-factor & 231.369 & 116 & 0.004 & 0.067 & 0.896 & 0.675 & 0.681 \\
\hline
\end{tabular}

RMSEA, root mean square error of approximation; GFI, goodness of fit index; AGFI, adjusted goodness of fit index; CFI, comparative fit index; TLI, Tucker-Lewis index; NFI, normed fit index. 


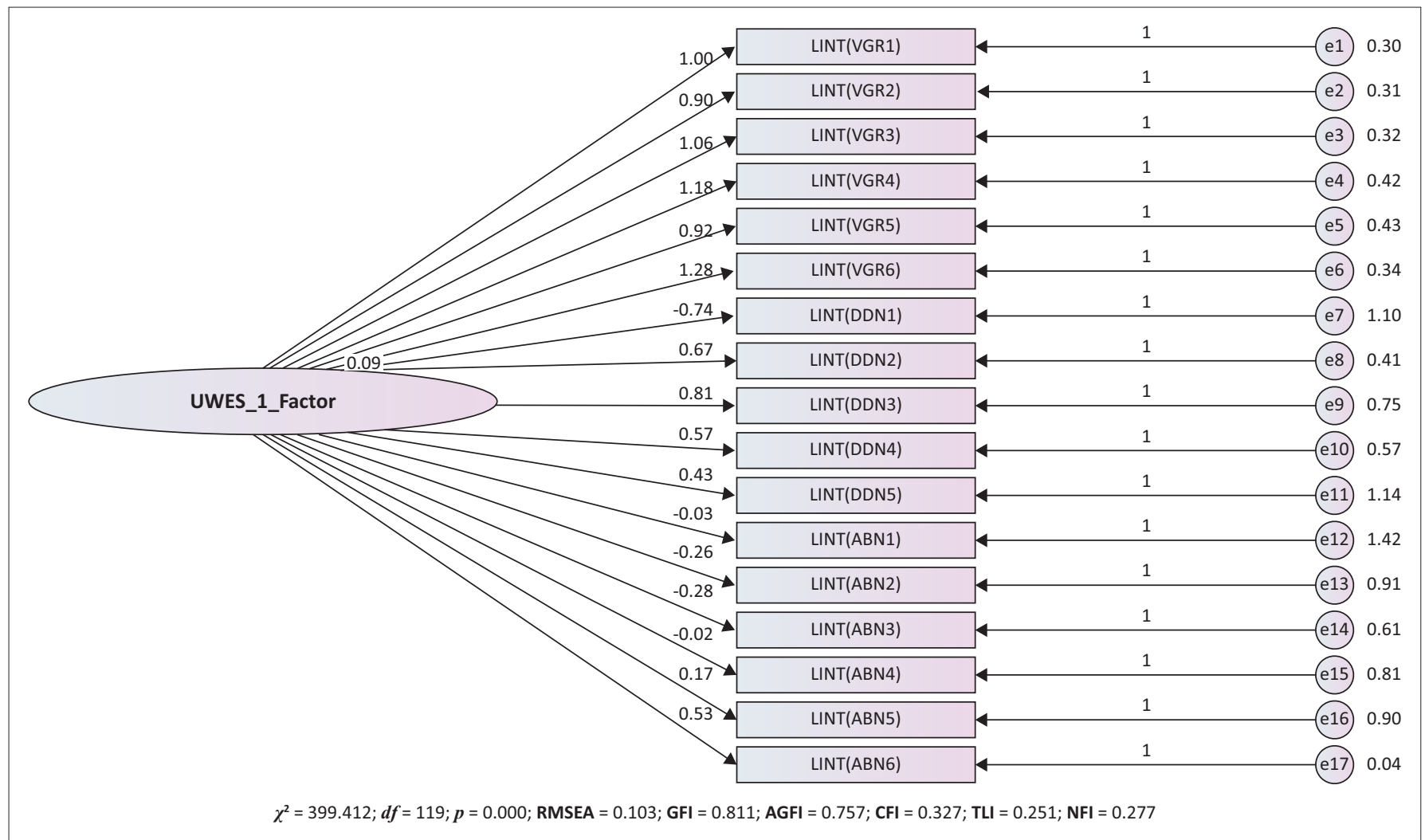

FIGURE 1: Uni-dimensional Utrecht Work Engagement Scale-17.

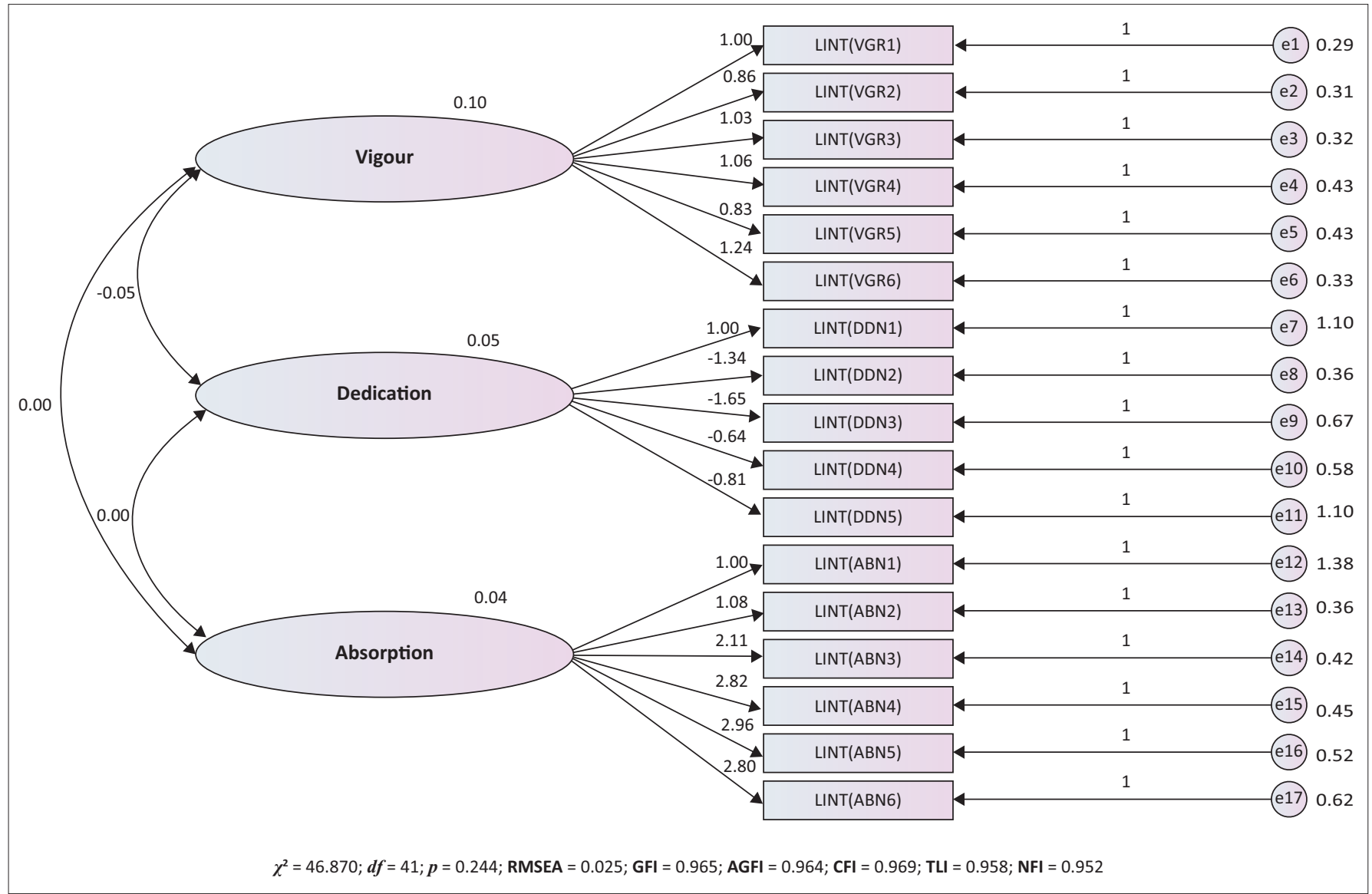

FIGURE 2: Tri-factor Utrecht Work Engagement Scale-17. 
TABLE 3: Confirmatory factor analysis results.

\begin{tabular}{lcccccccccc}
\hline Scale & $\chi \mathbf{2}$ & $\boldsymbol{d}$ & $\boldsymbol{p}$ & RMSEA & GFI & AGFI & CFI & TLI & NFI \\
\hline 3-factor/default model & 46.87 & 41 & 0.244 & 0.025 & 0.965 & 0.964 & 0.969 & 0.958 & 0.952 \\
\hline
\end{tabular}

RMSEA, root mean square error of approximation; GFI, goodness of fit index; AGFI, adjusted goodness of fit index; CFI, comparative fit index; TLI, Tucker-Lewis index; NFI, normed fit index.

TABLE 4: Standardised factor loadings, standard errors, and descriptive statistics for the UWES-17.

\begin{tabular}{|c|c|c|c|c|c|c|c|}
\hline Factorial structure & Scale item & CR & $\beta$ & $p$ & SE & Mean & SD \\
\hline \multirow[t]{3}{*}{ Vigour } & At my work, I feel bursting with energy & 85.134 & 0.691 & $* * *$ & 0.041 & 3.5200 & 0.62020 \\
\hline & At my job, I feel strong and vigorous & 86.487 & 0.599 & $* * *$ & 0.041 & 3.5573 & 0.61696 \\
\hline & When I get up in the morning, I feel like going to work & 80.512 & 0.466 & $* * *$ & 0.043 & 3.4800 & 0.64835 \\
\hline \multirow[t]{3}{*}{ Dedication } & I find the work that I do full of meaning and purpose & 34.087 & 0.095 & $* * *$ & 0.072 & 2.4438 & 1.07539 \\
\hline & I am enthusiastic about my job & 77.227 & 0.710 & $* * *$ & 0.045 & 3.4482 & 0.66976 \\
\hline & My job inspires me & 51.615 & 0.562 & $* * *$ & 0.060 & 3.0934 & 0.89900 \\
\hline \multirow[t]{5}{*}{ Absorption } & Time flies when I am working & 40.142 & 0.177 & $* * *$ & 0.080 & 3.1956 & 1.19410 \\
\hline & When I am working, I forget everything else around me & 53.880 & 0.312 & $* * *$ & 0.064 & 3.4400 & 0.95768 \\
\hline & I feel happy when I am working intensely & 74.684 & 0.639 & $* * *$ & 0.052 & 3.9111 & 0.78553 \\
\hline & I am immersed in my work & 64.889 & 0.635 & $* * *$ & 0.060 & 3.8933 & 0.90000 \\
\hline & It is difficult to detach myself from my job & 52.426 & 0.532 & $* * *$ & 0.066 & 3.4444 & 0.98551 \\
\hline
\end{tabular}

$\beta$, unstandardised beta regression coefficient; $p$, level of significance; SE, standard error of regression; SD, standard deviation.

$* * *, p<0.001$.

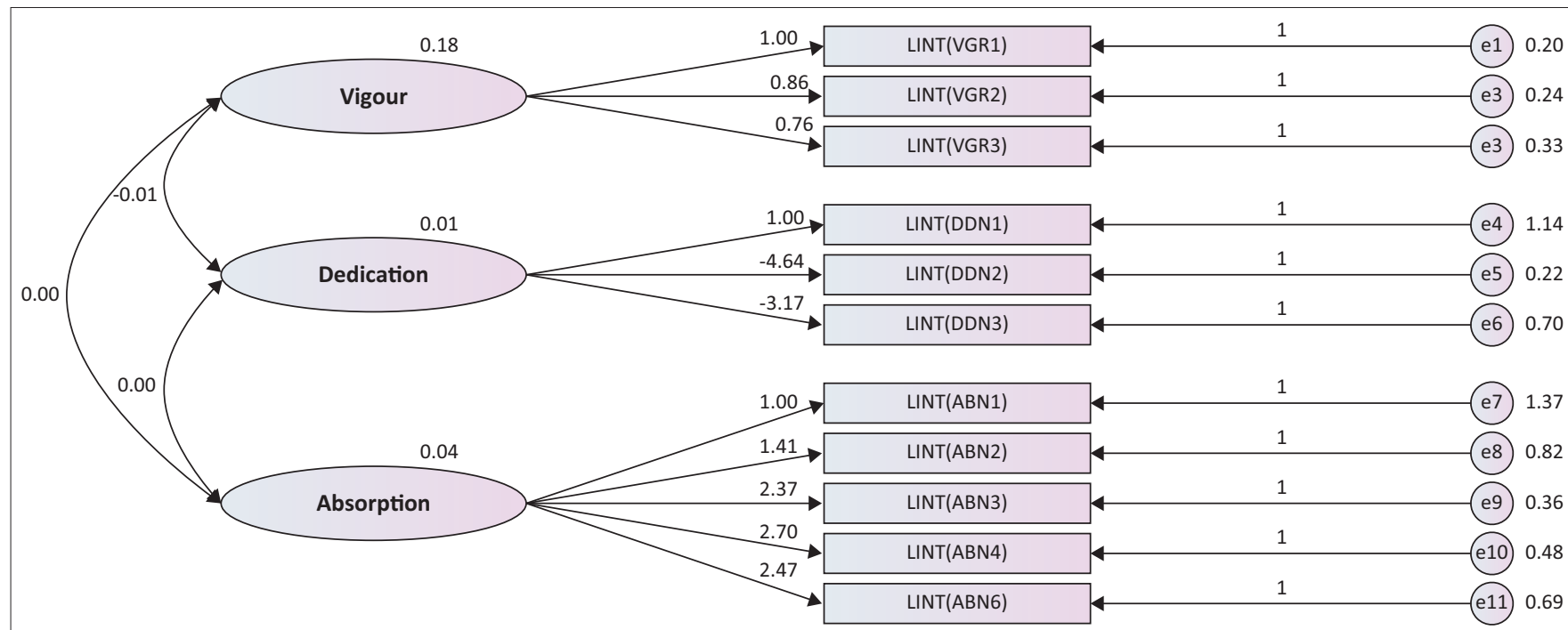

$\chi^{2}=46.870 ; d f=41 ; p=0.244 ; \mathrm{RMSEA}=0.25 ; \mathrm{GFI}=0.965 ; \mathrm{AGFI}=0.964 ; \mathrm{CFI}=0.969 ; \mathrm{TLI}=0.958 ; \mathrm{NFI}=0.952$

FIGURE 3: Tri-factor Utrecht Work Engagement Scale-Ug.

\section{Discussion}

The purpose of this study was to examine the psychometric properties of the UWES-17 in a Ugandan sample of primary school teachers. We aimed to evaluate the factorial validity in particular through comparison of the fit of the three-factor model to that of the one-factor model, which postulates that all items load on one single underlying construct. This study was inspired by the need for determination of the most robust and parsimonious technique of scoring this popular and extensively-used measure in an exclusive cultural setting. Substantial arguments exist in the extant literature as to whether the UWES-17, is a uni-dimensional psychological construct or a tri-factor construct. Findings of the CFA, offered support for a tri-factor UWES-17 model within the staff category of primary school teachers.

Findings confirmed an 11-item tri-factor UWES-17 model in Uganda's primary school sample (UWES-Ug). This is essentially in line with previous research that did not find evidence for a uni-dimensional construct of work engagement (Lathabhavan et al., 2017; Hadassah \& Balducci, 2013). This may suggest that among Ugandan employees (particularly the primary school teachers studied), work engagement measured by the UWES-17 still denotes a three underlying factor structure (vigour, dedication and absorption) rather than one. The uni-dimensional UWES-17 model displayed poor item discrimination. The items were poorly correlated (the correlations ranged from 0.30 to 0.47 ). The high correlations between the three factors - vigour, dedication and absorption, ranging between 0.89 and 0.94 , would point to a uni-dimensional structure, though the excellent fit of the data of the correlated tri-factor model provided support for the three different, although highly correlated factors. This finding is in line with the work of Schaufeli et al. (2006), who argue for uni-dimensional scale in multiple regression studies because the three sub-scales of vigour, dedication and 
absorption could lead to problems of collinearity and trifactor scales, in studies that rely on structural equation modelling in work engagement research like this one.

Further, inspection of the factor loadings for both unidimensional and tri-factor UWES-17 models provided superior statistical evidence for the tri-factor model owing to its superior and robust statistical fit indices. Given the high correlations between the 11-item tri-factor-confirmed work engagement model, the strong evidence of multidimensionality besides, the robust as well as acceptable model fit indices observed, we argue that the tri-factor model offers the finest statistical representation of the UWES-17 in the Ugandan sample. Also, in accordance with the suggestions of Nunnally and Bernstein (1994), the internal consistency of the 11-item three-factor UWES-Ug was adequate. The Cronbach's alpha coefficient $(\alpha)$ for all three factors (vigour, dedication and absorption) was substantially higher than 0.78. These findings indicate that the 11-item UWES-Ug version is a dependable measure of work engagement in the Ugandan milieu of primary school teachers. The demonstration that the UWES-17, developed in a particular cultural context, reveals same psychometric properties in other cultural contexts (Uganda) confirms its validity. The current findings are consistent with the past literature that that suggests that the tri-factor UWES-17 is an encouraging instrument for carrying out cross-cultural research on work engagement (cf. Balducci et al., 2010; Schaufeli \& Bakker, 2003; Schaufeli et al., 2006). Furthermore, the current findings also suggest that the UWES-Ug might be useful for measuring engagement levels in diverse organisation settings. Therefore, the tri-factor model of the UWES-Ug offers a unique benefit of being the most parsimonious and fast scoring tool that could be adopted for usage by education managers.

\section{Implications for theory and practice}

The current study presents significant implications for theory and practice. To begin with, the findings validate and extend the tri-factor structure of work engagement to developing countries by using data from a Ugandan sample. Therefore, an attempt has been taken towards appreciating the significance of the construct of work engagement within organisations (i.e., in Uganda's education sector). This research is important as work engagement studies in Uganda can further develop with the availability of a validated and reliable research tool. This is in response to the calls by Schaufeli and Bakker (2003), Schaufeli et al. (2006), Balducci et al. (2010) and Petrović et al. (2017), for testing of the UWES in different multi-cultural settings. Therefore, examining the psychometric properties of the instrument might hasten work engagement studies in Uganda. Moreover, this study attempted to address a dearth of academic works on work engagement from low resourced countries (Storm \& Rothmann, 2003; Vallières et al., 2017). This finding provides evidence of the 11-item tri-factor model of work engagement across a spectrum of occupational settings. Further, a revised and shorter measure of work engagement with only 11 items (UWES-Ug) offers a parsimonious understanding of the work engagement construct. With the 11-item work engagement instrument, managers could gain from the advantage of applying a shorter work engagement tool in occupational settings, with the likelihood of obtaining a more comprehensive understanding of work engagement. Also, from an organisational perspective, this study may be of help in the establishment of the extent to which work engagement represents the most appropriate scale. This might improve the usability of the instrument by the managers and thus boost employee productivity and organisation competitiveness.

\section{Limitations}

This study is not immune to limitations. The respondents were taken from only one sector, that is, primary education. Accordingly, there is a risk that the particular features of this sector (such as leadership, remuneration, location and professional training) influenced the study outcomes. This may call for future research on this area with multiple samples. Secondly, the cross-sectional research design adopted by this study, curtails comprehensive observations on the instrument's reliability and validity. Future studies should consider the longitudinal approach to unmask the validity of the tri-factor UWES-17 in the Ugandan context so that better conclusions on the adequacy of the scale can be drawn. Thirdly, this instrument validation study relied on self-reported data that may have caused the threat of common method bias. Storm and Rothmann (2003), point out that studies like this one which rely on self-report measures face this challenge.

\section{Conclusion}

This study underscores the context-specific validity of the UWES in the social and economic milieu of Uganda. The findings have demonstrated that the 11 item tri-factor UWES Uganda version has excellent psychometric properties and factorial structure in line with the theoretical model. Accordingly, this confirms that the UWES-Ug version is applicable in the Ugandan context in empirical settings and for practical aims. On account of the established research findings it can be inferred that in Uganda work engagement is a tri-dimensional construct comprising vigour, dedication and absorption.

\section{Acknowledgements}

We are grateful to the Mayuge district local government leadership of Uganda for having allowed us to collect data from their staff, which enabled this research project to be a success. In a similar vein, we are immensely grateful to our respective Deans (Busitema University and ICT University), who gave us additional opportunities outside the traditional roles within the faculties to undertake this study. Lastly, we are much indebted to the anonymous reviewers who provided extra insights that led to the improvement of this article. 


\section{Competing interests}

There were no competing interests in the process of developing this article.

\section{Authors' contributions}

T.S.M. was the project leader, and responsible for conceptualisation, and project design, data collection and analysis. I.A.M. was responsible for project design, data analyses and report writing.

\section{Funding information}

This was a self-funded project.

\section{Data availability statement}

Data sharing is not applicable to this article as no new data were created or analysed in this study.

\section{Disclaimer}

The views and opinions expressed in this article are those of the authors and do not necessarily reflect the official policy or position of any affiliated agency of the authors.

\section{References}

Ahmed, U., Majid, A., \& Zin, M. (2016). Construct validation of 17-item Utrecht University Work Engagement Scale amongst the white collar employees of Malaysian Universities. International Journal of Academic Research in Business and Social Sciences, 6(5), 306-312. https://doi.org/10.6007/IJARBSS/v6-i5/2144

Alok, K. (2013). Work engagement in India: A factorial validation study of UWES-9 scale. Management and Labour Studies, 38 (1\&2), 53-62. https://doi.org/ 10.1177/0258042X13491478

Amin, E.M. (2005). Social science research: Conception, methodology and analysis Kampala: Makerere University Press.

Arbuckle, J. (2012). Amos 18 user's guide. Chicago, IL: Amos Development Corporation.

Bakker, A., Schaufeli, W., Leiter, M., \& Taris, T. (2008). Work engagement: An emerging concept in occupational health psychology. Work \& Stress, 22(3), 187-200. https://doi.org/10.1080/02678370802393649

Balducci, C., Fraccaroli, F., \& Schaufeli, W.B. (2010). Psychometric properties of the Italian version of the Utrecht work engagement scale (UWES-9), a cross-cultural analysis. European Journal of Psychological Assessment, 26, 143-149. https://doi. org/10.1027/1015-5759/a000020

Bollen, K.A. (1989). Structural equations with latent variables. New York: Wiley.

Browne, M.W., \& Cudeck, R. (1993). Alternative ways of assessing model fit. In K. Bollen \& J. Long (Eds.), Testing structural equation models (pp. 136-162) Newbury Park, CA: Sage.

Carr, S., Eltayeb, S., MacLachlan, M., Marai, L., McAuliffe, E., \& McWha, I. (2012). Aiding international development: Some fresh perspectives from organisational psychology. In J. Olson-Buchanan, L. Bryan, \& L. Thompson (Eds.), Using I-O psychology for the greater good: Helping those who help others. Washington, DC: American Psychological Association.

De Bruin, G., Hill, C., Henn, C., \& Muller, K.-P. (2013). Dimensionality of the UWES-17: An item response modelling analysis. SA Journal of Industrial Psychology/SA Tydskrif vir Bedryfsielkunde, 39(2), 1-8. https://doi.org/10.4102/sajip.v39i2.1148

Fong, T., \& Ho, R. (2015). Dimensionality of the 9-item Utrecht work engagement scale revisited: A Bayesian structural equation modeling approach. Journal of Occupational Health, 57(4), 353-358. https://doi.org/10.1539/joh.15-0057-OA

Hadassah, L.-O., \& Balducci, C. (2013). Psychometric properties of the Hebrew version of the Utrecht Work Engagement Scale (UWES-9). European Journal of Psychological Assessment, 29(1), 58-63. https://doi.org/10.1027/1015-5759/a000121

Halbesleben, J. (2010). A meta-analysis of work engagement: Relationships with burnout, demands, resources, and consequences. In A. Bakker, \& M. Leite (Eds.), Work engagement: A handbook of essential theory and research (Vol. 8, pp. 102-117), New York: Psychology Press.

Hinkin, T.R. (1998). A brief tutorial on the development of measures for use in survey questionnaires. Organizational Research Methods, 2(1), 104-121. https://doi. org/10.1177/109442819800100106

$\mathrm{Hu}$ L., \& Bentler, P.M. (1998). Fit indices in covariance structure modeling: Sensitivity to underparameterized model misspecification. Psychological Methods, 3(4), 424-453. https://doi.org/10.1037/1082-989X.3.4.424
Hu, L., \& Bentler, P.M. (1999). Cutoff criteria for fit indexes in covariance structure analysis: Conventional criteria versus new alternatives. Structural Equation Modeling, 6, 1-55. https://doi.org/10.1080/10705519909540118

India, B. (2019, July 11). Attrition in Indian BPO Industry. Retrieved from http://www. bpoindia.org/research/attrition.shtml

Kagolo, F. (2013, October 2). Over 10,000 teachers quit each year for greener pasture. New Vision. Retrieved from https://www.newvision.co.ug/new_vision/news/ 1333054/-teachers-quit-greener-pasture.

Kim, K. (2007). Structural equation modeling. Seoul: Hannarae.

Klassen, R., Wilson, E., Siu, A.F.Y., Hannok, W., Wong, M.W., Wongsri, N., ... Jansem, A. (2013). Preservice teachers' work stress, self-efficacy, and occupational commitment in four countries. European Journal of Psychology of Education, 28, 1289-1309. https://doi.org/10.1007/s10212-012-0166-x

Kline, R. (2011). Principles and practice of structural equation modelling (3rd ed.). New York: Guilford Press.

Konermann, J. (2012). Teachers' work engagement: A deeper understanding of the role of job and personal resources in relationship to work engagement, its antecedents, and its outcomes. Enschede: Universiteit Twente. https://doi. org/10.3990/1.9789036533027

Krejcie, V.R., \& Morgan, D. (1970). Determining sample size for research activities. Educational and Psychological Measurement, 30, 688. https://doi.org/10.1177/ 001316447003000308

Kulikowski, K. (2017). One, two or three dimensions of work engagement? Testing the factorial validity of the Utrecht Work Engagement Scale on a sample of Polish employees. International Journal of Occupational Safety and Ergonomics. https:// doi.org/10.1080/10803548.2017.1371958

Lathabhavan, R., Balasubramanian, S., \& Natarajan, T. (2017). A psychometric analysis of the Utrecht Work Engagement Scale in Indian banking sector. Industrial and Commercial Training, 49(6), 296-302. https://doi.org/10.1108/ ICT-04-2017-0031

MoES. (2014a). Educational management information system. Kampala: Ministry of Education and Sports.

MoES. (2014b). Teacher issues in Uganda: A shared vision for an effective teachers policy. Ministry of Education and Sports. Kampala: UNESCO - IIEP Pôle de Dakar.

MoES. (2016). Educational abstract. Kampala: Education Policy and Planning Department.

Nunnally, J.C., \& Bernstein, I.H. (1994). Psychometric theory (3rd edn.). Sydney: McGraw Hill.

OECD. (2005). OECD annual report: 45th anniversary. Paris: OECD Publications.

Petrović, I.B., Vukelić, M., \& Čizmić, S. (2017). Work engagement in Serbia: Psychometric properties of the Serbian version of the Utrecht Work Engagement Scale (UWES). Frontiers in Psychology, 8(1799), 1-11. https://doi.org/10.3389/ fpsyg.2017.01799

Podsakoff, P., MacKenzie, S.B., \& Podsakoff, N. (2003). Common method biases in behavioral research: A critical review of the literature and recommended
remedies. Journal of Applied Psychology, 88(5), 879-903. https://doi.org/ remedies. Journal of Applied

Podsakoff, P., MacKenzie, S.B., \& Podsakoff, N (2012). Sources of method bias in social science research and recommendations on how to control it. Annual Review of Psychology, 63(1), 539-569. https://doi.org/10.1146/annurev-psych-120710-100452

Salanova, M., Agut, S., \& Peiró, J.M. (2005). Linking organizational resources and work engagement to employee performance and customer loyalty: The mediation of service climate. Journal of Applied Psychology, 90(6), 1217. https://doi. service climate. Journal of Applie
org/10.1037/0021-9010.90.6.1217

Sasmoko, Doringin F., Indrianti Y., Goni A.M., \& Ruliana P. (2018). Indonesian Teacher Engagement Index (ITEI): An Emerging Concept of Teacher Engagement in Indonesia. IOP Conf Ser Mater Sci Eng, 306(1). https://doi.org/10.1088/1757899X/306/1/012119

Satorra, A., \& Bentler, P.M. (2001). A scaled difference chi-square test statistic for moment structure analysis. Psychometrika, 66, 507-514. https://doi.org/10.1007/ BF02296192

Sautier, L., Scherwath, A., Weis, J., Sarkar, S., Bosbach, M., Schendel, M., ... Mehnert, A. (2015). Assessment of work engagement in inpatient and rehabilitative oncological settings: Psychometric properties of the German version of the Utrecht Work Engagement Scale 9 (UWES-9). Die Rehabilitation, 54, 1-7. https:// doi.org/10.1055/s-0035-1555912

Schaufeli, W., \& Bakker, A.B. (2003). Test manual for the Utrecht Work Engagement Scale. Unpublished manuscript, Utrecht University, the Netherlands. Retrieved from http://www.schaufeli.com.

Schaufeli, W., Bakker, A.B., \& Salanova, M. (2006). The measurement of work engagement with a short questionnaire: A cross-national study. Educational and Psychological Measurement, 66(4), 701-716. https://doi.org/10.1177/ 0013164405282471

Schaufeli, W., Salanova, M., Gonzalez-Roma, V., \& Bakker, A. (2002). The measurement of engagement and burn out: $A$ confirmative analytic approach. Journal of Happiness Studies, 3, 71-93. https://doi.org/10.1023/ A:1015630930326

Seppälä, P. (2013). Work engagement: Psychometrical, psychosocial, and psychophysiological approach. Faculty of Social Sciences, University of Jyväskylä. Jyväskylä: University Library of Jyväskylä.

Seppälä, P., Mauno, S.F., Hakanen, J., Kinnunen, U., Tolvanen, A., \& Schaufeli, W. (2009). The construct validity of the Utrecht Work Engagement Scale: Multisample and longitudinal evidence. Journal of Happiness Studies, 10, 459-481. https://doi. org/10.1007/s10902-008-9100-y 
Shimazu, A., Schaufeli, W.B., Kosugi, S., Suzuki, A., Nashiwa, H., Kato, A., ... KitaokaHigashiguchi, K. (2008). Work engagement in Japan: Validation of the Japanese version of the Utrecht Work Engagement Scale. Applied Psychology: An International Review, 57(3), 510-523. https://doi.org/10.1111/j.1464-0597.2008.00333.x

Sinval, J., Pasian, S.Q., \& Marôco, J. (2018). Brazil-Portugal transcultural adaptation of the UWES-9: Internal consistency, dimensionality, and measurement invariance. Frontiers in Psychology, 9(353), 1-18. https://doi.org/10.3389/ invariance. Frontiers

Storm, K. \& Rothmann, S. (2003). A psychometric analysis of the Utrecht Work Engagement Scale in the South African Police Service. SA Journal of Industrial Psychology, 29(4), 62-70. https://doi.org/10.4102/sajip.v29i4.129

Vallières, F., \& McAuliffe, E. (2015). Reaching MDGs 4 and 5: The application of organizational psychology to maternal and child health programme sustainability in Sierra Leone. In I. McWha-Herrmann, D.C. Maynard, \& M. O'Neill Barry (Eds.) Contribution of humanitarian work psychology to the sustainable development goals (pp. 15-27). London: Routledge.
Vallières, F., McAuliffe, E., Hyland, P., Galligan, M., \& Ghee, A. (2017). Measuring work engagement among community health workers in Sierra Leone: Validating the Utrecht Work Engagement Scale. Journal of Work and Organizational Psychology, 33, 41-46.

Vazquez, A., dos Santos Magnan, E., Pacico, J., \& Hutz, C. (2015). Adaptation and validation of the Brazilian version of the Utrecht Work Engagement Scale. Psico-USF, Bragança Paulista, 20(2), 207-217. https://doi.org/10.1590/1413-82712015200202

Williams, L., \& McGonagle, A. (2016). Four research designs and a comprehensive analysis strategy for investigating common method variance with self-report measures using latent variables. Journal of Business and Psychology, 31, 339-359. https://doi.org/10.1007/s10869-015-9422-9

Wurie, H., Samai, M., \& Witter, S. (2016). Retention of health workers in rural Sierra Leone: Findings from life histories. Human Resources for Health, 14(3), 1-15. https://doi.org/10.1186/s12960-016-0099-6

Yamane, T. (1967). Statistics, an introductory analysis (2nd edn.). New York: Harper and Row. 